\title{
Influence of oxide and alloy formation on the Electrochemistry of Ti deposition from the NaCl-KCl-NaF-K-2 TiF6 melt reduced by metallic Ti
}

\author{
Barner, Jens H. Von; Precht Noyé, Pernille; Barhoun, A; Lantelme, Frederic
}

Published in:

Journal of The Electrochemical Society

Link to article, DOI:

$10.1149 / 1.1833313$

Publication date:

2005

Document Version

Publisher's PDF, also known as Version of record

Link back to DTU Orbit

Citation (APA):

Barner, J. H. V., Precht Noyé, P., Barhoun, A., \& Lantelme, F. (2005). Influence of oxide and alloy formation on the Electrochemistry of Ti deposition from the NaCl-KCl-NaF-K-2 TiF6 melt reduced by metallic Ti. Journal of The Electrochemical Society, 152(1), C20-C26. https://doi.org/10.1149/1.1833313

\section{General rights}

Copyright and moral rights for the publications made accessible in the public portal are retained by the authors and/or other copyright owners and it is a condition of accessing publications that users recognise and abide by the legal requirements associated with these rights.

- Users may download and print one copy of any publication from the public portal for the purpose of private study or research.

- You may not further distribute the material or use it for any profit-making activity or commercial gain

- You may freely distribute the URL identifying the publication in the public portal 


\title{
(4tS) Influence of Oxide and Alloy Formation on the Electrochemistry of Ti Deposition from the NaCl-KCl-NaF-K $\mathrm{K}_{2} \mathrm{TiF}_{6}$ Melt Reduced by Metallic Ti
}

\author{
J. H. von Barner, ${ }^{\mathrm{a}, \mathrm{z}}$ P. Noyé, ${ }^{\mathrm{a}}$ A. Barhoun, ${ }^{\mathrm{b}}$ and F. Lantelme ${ }^{\mathrm{c}, *}$ \\ ${ }^{a}$ Department of Chemistry, Technical University of Denmark, DK 2800 Lyngby, Denmark \\ ${ }^{b}$ Department de Chimie, Université Abdelmalek Essaâdi, 93002 Tétouan, Maroc \\ ${ }^{c}$ LI2C-Electrochemie, Pierre et Marie Curie Université, F-75252 Paris, Cedex 05, France
}

The redox reactions in $\mathrm{KCl}-\mathrm{NaCl}-\mathrm{NaF}-\mathrm{K}_{2} \mathrm{TiF}_{6}$ melts reduced by titanium metal have been studied by cyclic voltammetry and chronopotentiommetry. At platinum and nickel electrodes waves due to alloy formation were seen preceding the $\mathrm{Ti}(\mathrm{III}) \rightarrow \mathrm{Ti}$ metal deposition wave. The presence of oxide species could be detected as waves on voltammograms performed with platinum electrodes. Deposits on nickel plates in general consisted of multiphase Ni-Ti layers. By varying the deposition potential outer layers with compositions ranging from pure titanium over NiTi to nickel-rich alloys such as $\mathrm{Ni}_{3}$ Ti could be obtained. Pulse plating produced the best titanium coating. With constant potential electrolyses it was also possible to deposit titanium diboride coatings of high quality from the mixed chloride-fluoride melts.

(C) 2004 The Electrochemical Society. [DOI: 10.1149/1.1833313] All rights reserved.

Manuscript submitted February 24, 2004; revised manuscript received June 8, 2004. Available electronically December 1, 2004.

Titanium and titanium alloys and compounds have recently attracted great interest because of their many uses, e.g., in corrosion protection, as electrodes for metal production, and for medical purposes. The almost equimolar Ni-Ti alloy (nitinol) has memory shape properties, and it also seems to exhibit good biocompatibility ${ }^{1,2}$ thus being a promising candidate as an implant material. Another interesting titanium compound is $\mathrm{TiB}_{2}$. In the last few years, because of a high corrosion resistance and electrical conductivity, electrodes coated with $\mathrm{TiB}_{2}$ have proved to be useful as aluminum wettable cathodes. $^{3}$

Due to its negative deposition potential titanium cannot be electrochemically deposited from aqueous media. In this respect fused salt electrolyses can be an interesting method for producing coatings of titanium metal as well as titanium alloys and compounds. Certainly the electrochemistry of titanium has been studied in a number of different molten salt media comprising all-chloride, all-fluoride, and mixed chloride-fluoride solvents.

Among the all-fluoride melts especially the LiF-NaF-KF eutectic (FLINAK) has often been used as a solvent in investigations on the electrochemistry and plating with titanium. In this melt a two-step reduction of $\mathrm{Ti}(\mathrm{IV})$ to titanium metal, $\mathrm{Ti}(\mathrm{IV}) \rightarrow \mathrm{Ti}(\mathrm{III}) \rightarrow \mathrm{Ti}$ is known to proceed. ${ }^{4,5}$ The electrochemistry in pure chloride melts, like $\mathrm{LiCl}-\mathrm{KCl}$ or $\mathrm{NaCl}-\mathrm{KCl}$, is more complicated. Here the reduction of $\mathrm{Ti}(\mathrm{IV})$ typically takes place in three steps, ${ }^{6-8} \mathrm{Ti}(\mathrm{IV})$ $\rightarrow \mathrm{Ti}(\mathrm{III}) \rightarrow \mathrm{Ti}(\mathrm{II}) \rightarrow \mathrm{Ti}$. When fluoride ions are added to chloride melts the higher oxidation states of the metals will often be stabilized due to formation of fluorocomplexes. In the case of titanium the same two-step reduction mechanism as in all fluoride melts was found in a $\mathrm{KCl}-\mathrm{NaCl}$ molten salt bath, ${ }^{7,9,10}$ when sufficient fluoride were present $(\mathrm{F} / \mathrm{Ti}$ molar ratio $\geqslant 6)$.

Concerning plating it has been possible to obtain titanium coatings of good quality on, e.g., iron ${ }^{5}$ and steel ${ }^{11}$ with FLINAK melts as the supporting liquid. At the temperatures applied (typically around $700^{\circ} \mathrm{C}$ ) interdiffusion of titanium with the metallic substrates often plays an important role resulting in a good adherence of the titanium outer layer. Such an alloy formation has been observed when titanium was deposited from FLINAK on nickel ${ }^{5}$ and copper ${ }^{12}$ substrates. The attempts to produce titanium surface layers from pure chloride melts have been less successful. Only in one case have coherent deposits of titanium been obtained from chloride melts; however the current efficiency was low and sludge formation occurred. ${ }^{8}$ The difficulties are probably largely related to the Ti(II)

* Electrochemical Society Active Member.

z E-mail: jvb@kemi.dtu.dk oxidation state, e.g., chemical disproportion of $\mathrm{Ti}(\mathrm{II})$ to $\mathrm{Ti}(\mathrm{III})$ and powdery titanium metal is likely to happen. ${ }^{7,8}$ Thus although alkali chlorides are cheaper, less corrosive, and less toxic compared to alkali fluorides, electrodeposition of titanium from all-chloride melts seems troublesome. The use of mixed chloride-fluoride melts as supporting liquid offers an interesting alternative to the fluoride and chloride melts. They are in general less toxic and more soluble in water than the fluoride melts, which makes the dissolution of adherent solidified melt after electrolyses easier. Only a few works in the literature deal with deposition of titanium from such melts, e.g., the $\mathrm{KCl}-\mathrm{NaCl}-\mathrm{LiCl}$ eutectic with $\mathrm{K}_{2} \mathrm{TiF}_{6}$ added has been applied to produce titanium coatings on steel. ${ }^{13}$ This substrate seems to be the only one which has been investigated in connection with mixed chloride-fluoride melts.

$\mathrm{TiB}_{2}$ can be plated from fluoride melts, and we have previously ${ }^{10}$ attempted to make deposits from $\mathrm{KCl}-\mathrm{NaCl}-\mathrm{NaF}$ melts, however the resulting layer was poorly crystallized. Kaptay and Kuznetsov ${ }^{14}$ give references to most of the work done so far on $\mathrm{TiB}_{2}$ deposition from molten salts in a recent review.

A major problem when depositing metallic surface layers from molten salts is the effects due to oxide impurities in the salt bath. The presence of oxide often results in deposits of poor quality ranging from modifications of the metallic crystal structure by interstitial oxygen to formation of metal oxides. It has been reported ${ }^{12}$ that such oxide contamination caused porous surface layers and even formation of titanium oxides during deposition of titanium from FLINAK melts. Concerning investigations on the fundamental electrochemistry of titanium in alkali halide melts with oxide present only one paper ${ }^{9}$ mentions effects that may be caused by oxide contamination, and the knowledge about which species that form is also very scarce.

The aim of the present work is to explore the possibilities for appling $\mathrm{KCl}-\mathrm{NaCl}-\mathrm{NaF}$ melts to produce various coatings containing titanium, e.g., titanium metal, nickel-titanium alloys, and $\mathrm{TiB}_{2}$. Special attention is given to clarify which titanium-nickel alloys may be formed on nickel substrates by varying the deposition parameters. Further we want to investigate if the presence of oxide, possibly in the form of titanium oxofluoro species, can be detected electrochemically in the molten chloride-fluoride salt bath.

\section{Experimental}

The solvent $(\mathrm{NaCl}, 60.5 \mathrm{~mol} \%$; KCl, $22.5 \mathrm{~mol} \%$ and $\mathrm{NaF}, 17$ mol \%) was made from commercial pro analyses salts (Merck) dried in vacuum at $130^{\circ} \mathrm{C}$. Before addition of the solutes the solvent was further purified in the electrochemical setup by heating up to $350^{\circ} \mathrm{C}$ under vacuum and subsequently under an argon atmosphere raising 
the temperature beyond the melting point. As previously ${ }^{10}$ the melt was pre-electrolyzed for $8 \mathrm{~h}$ with a carbon electrode $(I=30 \mathrm{~mA})$ to remove oxide impurities and subsequently checked by cyclic voltammetry on gold and glassy carbon electrodes. After this treatment an oxide ion concentration of less than $0.1 \mathrm{~mol} \%$ was found.

$\mathrm{K}_{2} \mathrm{TiF}_{6}$ (Johnson-Matthey) was recrystallized from hydrogen fluoride, added to the melt and reduced to $\mathrm{Ti}^{3+}$ by titanium granules (high purity, Johnson-Matthey) at approximately $700^{\circ} \mathrm{C}$. The concentration of titanium in the melts $\left(C_{\mathrm{Ti}}\right)$ is given with respect to the amount after reduction with the titanium metal. $\mathrm{Na}_{2} \mathrm{CO}_{3}$ was used as the oxide source assuming that the salt disproportionated to $\mathrm{Na}_{2} \mathrm{O}$ and $\mathrm{CO}_{2}$ at the temperature of the melts (around $700^{\circ} \mathrm{C}$ ). The molten salt samples were contained in glassy carbon crucibles placed inside a Hastelloy device with tight leads for the electrodes through a lid. The setup has been described in detail previously. ${ }^{15}$

The nickel and tungsten working electrodes were wires (Johnson-Matthey) with diameters of 2 and $1 \mathrm{~mm}$, respectively. They were immersed $10 \mathrm{~mm}$ into the melt.

The electrochemical measurements were performed with a potentiostat (Tacussel PRT20-10) and a programmer (Tacussel GSTP4). The measurements were registrated with an oscilloscope (Nicolet 310) and a X-Y recorder (Hewlett Packard).

The $\mathrm{Pt}^{2+}(1 \mathrm{M}) / \mathrm{Pt}$ couple has been chosen as an internal reference system, and potentials refer to this redox couple unless otherwise stated.

The electroplated deposits were investigated using a Philips scanning electron microscope (SEM) 505 equipped with an energy dispersive X-ray analyser (EDAX). The X-ray diffraction analyses were carried out with a Philips PW 1050/1025 diffractometer. In all cases $\mathrm{Cu} \mathrm{K} \alpha$ radiation was applied.

\section{Results and Discussion}

Voltammetry.-It is important to be aware that signals due to alloy formation between titanium and the materials applied as working electrodes may occur at the voltammograms. In FLINAK melts such waves has been observed for copper, ${ }^{12}$ platinum, ${ }^{4}$ glassy carbon, ${ }^{4}$ and nickel ${ }^{5}$ electrodes. It was previously shown that no alloy formation with titanium occurred, when tungsten working electrodes were applied. ${ }^{8-10}$ Thus in this case only the waves from the redox reactions of titanium are seen on the voltammograms. Figure 1A shows such a voltammogram performed on a $\mathrm{K}_{2} \mathrm{TiF}_{6}-\mathrm{NaCl}-\mathrm{KCl}-\mathrm{NaF}$ melt reduced with titanium metal. Besides the signal due to oxidation of the tungsten electrode, two reduction waves that can be attributed to titanium species are seen. The most positive, $\mathrm{R}_{1}$ at around $-1.26 \mathrm{~V}$, are due to reduction of a $\mathrm{Ti}(\mathrm{IV})$ species to $\mathrm{Ti}(\mathrm{III})$, the wave $\mathrm{Ox}_{1}$ corresponds to the reverse reaction. The second one, $R_{2}$ near $-2.73 \mathrm{~V}$, can be related to deposition of titanium metal and is linked to the typical stripping wave $\mathrm{Ox}_{2}$. The standard potentials at $720^{\circ} \mathrm{C}$ for these reactions can be calculated to -1.104 and $-2.324 \mathrm{~V}$, respectively. These values agree well with those that we found previously. ${ }^{10}$

A voltammogram of the same melt at a nickel electrode is presented in Fig. 1B. In order to deduce which reduction and oxidation waves were coupled we also recorded voltammograms with other potential windows (not shown on Fig. 1B). At the positive limit the oxidation of the nickel electrode can be observed $(-0.965 \mathrm{~V})$. The $\mathrm{Ti}(\mathrm{III}) / \mathrm{Ti}(\mathrm{IV})$ oxidation wave can be seen as a shoulder on the nickel oxidation wave. Compared to voltammograms performed with tungsten electrodes (Fig. 1A), two new reduction waves can be seen, $R_{3}$ and $\mathrm{R}_{4}$ at -2.21 and $-2.61 \mathrm{~V}$, respectively. Also during the reverse scan additional waves appear. The wave $\mathrm{Ox}_{3}$ obviously corresponds to $\mathrm{R}_{3}$, whereas the two oxidation waves $\mathrm{Ox}_{4}$ and $\mathrm{Ox}_{4}^{\prime}$ both seem to be connected to $R_{4}$. At approximately $-2.75 \mathrm{~V}$ a weak wave, $\mathrm{R}_{2}$ can be seen. The shoulder $\mathrm{Ox}_{2}$, which appears as the first oxidation signal on the reverse scan, corresponds to $R_{2}$. We assign these waves to deposition/oxidation of titanium metal since $R_{2}$ occurs at a potential close to the one we found for reduction of Ti(III) to el-

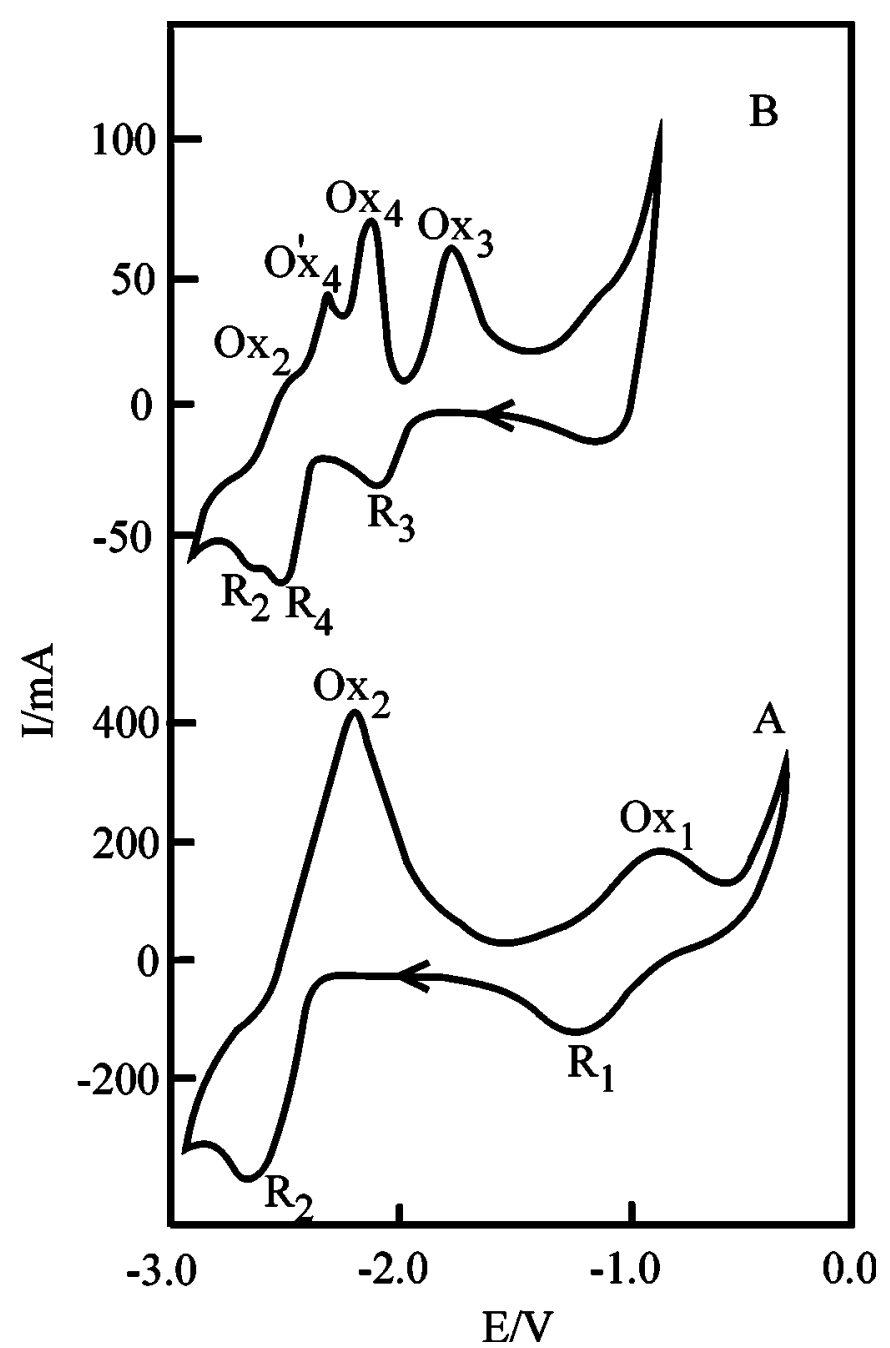

Figure 1. Cyclic voltammograms of a $\mathrm{K}_{2} \mathrm{TiF}_{6}-\mathrm{NaCl}-\mathrm{KCl}-\mathrm{NaF}$ melt with titanium metal added. $C_{\mathrm{Ti}}=0.21 \mathrm{~mol} / \mathrm{L}$; temperature $720^{\circ} \mathrm{C}$ and scan rate 1 $\mathrm{V} / \mathrm{s}$. (A) tungsten electrode, area $=0.61 \mathrm{~cm}^{2}$, reverse potential $-2.95 \mathrm{~V}$ (vs. $\mathrm{Pt} / \mathrm{Pt}^{2+}$ ) and $(\mathrm{B})$ nickel electrode, area $=0.30 \mathrm{~cm}^{2}$, reverse potential -2.93 $\mathrm{V}\left(\right.$ vs. $\left.\mathrm{Pt} / \mathrm{Pt}^{2+}\right)$.

ementary titanium with a tungsten electrode (Fig. 1A). The picture with reduction waves preceding the wave for deposition of the pure metal is typical for alloy formation between the electrode and the deposited metal.

When the scan rate is decreased (Fig. 2) the reduction potentials remains almost the same but the waves appear more separated. It further seems that $R_{2}$ becomes more pronounced relative to $R_{3}$ and $\mathrm{R}_{4}$. This trend can also be observed on the oxidation waves, where $\mathrm{Ox}_{2}$ grows relative to $\mathrm{Ox}_{4}$ with decreasing scan rates. The change in the shape of the voltammograms is probably due to the change in the thickness of the alloy layers when the sweep rate is varied. At fast sweep rates only a few atomic layers are involved in the electrochemical reactions. It is known ${ }^{16}$ that under such circumstances the intermetallic diffusion at the surface proceeds faster than is the case in the bulk of the substrate. At slow sweep rates the accumulation process of titanium metal at the electrode surface becomes more significant than the diffusion into the substrate, thus it is expected that the peaks due to deposition/dissolution of the metal would grow with decreasing sweep rates.

According to the phase diagram of the Ni-Ti system ${ }^{17}$ the phases $\mathrm{Ni}_{3} \mathrm{Ti}, \mathrm{NiTi}, \mathrm{NiTi}_{2}$ exist. It seems reasonable to relate the peaks $\mathrm{Ox}_{3}, \mathrm{Ox}_{4}$, and $\mathrm{Ox}_{4}^{\prime}$ to the oxidation of these compounds. Decreasing the sweep rate from 1 (Fig. 1B) to $0.1 \mathrm{~V} / \mathrm{s}$ (Fig. 2A) makes the 


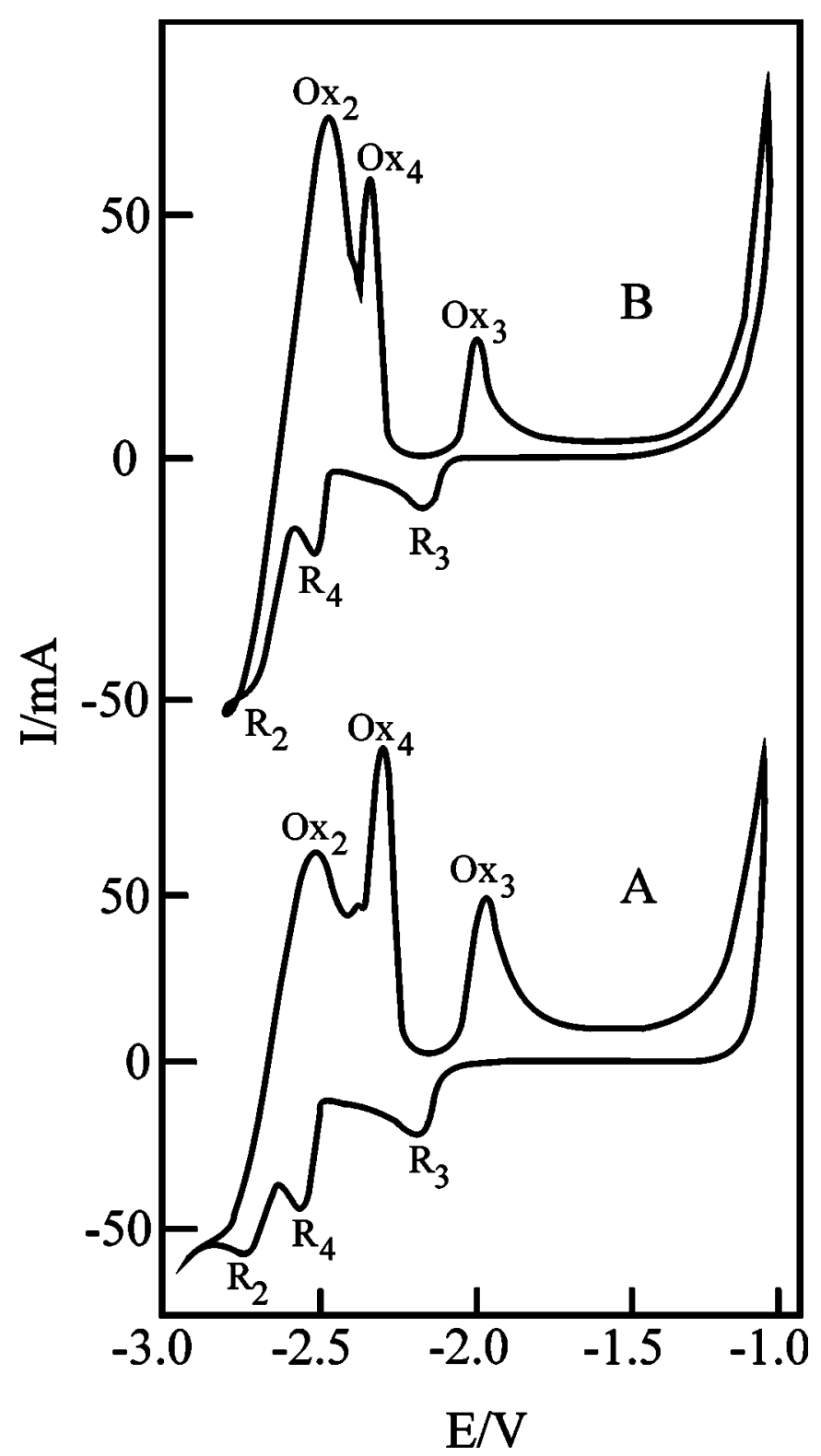

Figure 2. Cyclic voltammograms at different scan rates of a $\mathrm{K}_{2} \mathrm{TiF}_{6}-\mathrm{NaCl}-\mathrm{KCl}-\mathrm{NaF}$ melt reduced with titanium metal. Nickel working electrode $\left(\right.$ area $\left.=0.30 \mathrm{~cm}^{2}\right)$, temperature, $720^{\circ} \mathrm{C} ; C_{\mathrm{Ti}}=0.21 \mathrm{~mol} / \mathrm{L}$. Scan rates: (A) 0.1 and (B) $0.02 \mathrm{~V} / \mathrm{s}$.

peak $\mathrm{Ox}_{4}^{\prime}$ less intensive and with a sweep rate at $0.02 \mathrm{~V} / \mathrm{s}$ (Fig. 2B) it becomes hardly visible. This behavior seems to be in agreement with the fact that we never obtained a definite layer of $\mathrm{NiTi}_{2}$ during our deposition experiments at fixed potentials, whatever potential we applied. This suggests that $\mathrm{NiTi}_{2}$ is only a transition state during the electrochemical deposition. This is interesting to compare with previous results by Robin et al. ${ }^{5}$ obtained at nickel electrodes on Ti(III) dissolved in FLINAK melts with a scan rate of $0.1 \mathrm{~V} / \mathrm{s}$ (i.e., the same as in Fig. 2A). On the oxidation part of their voltammogram the pattern with three oxidation waves seems to be similar to what we find, however, the reduction part differs since they ${ }^{5}$ only assign one wave due to alloy formation.

Chronopotentiometry and thermodynamic estimations.-Chronopotentiometry can often supply useful information about the alloy formation at the surface of an electrode. In Fig. 3 we present a current reversal chronopotentiogram at a nickel electrode. In addi-

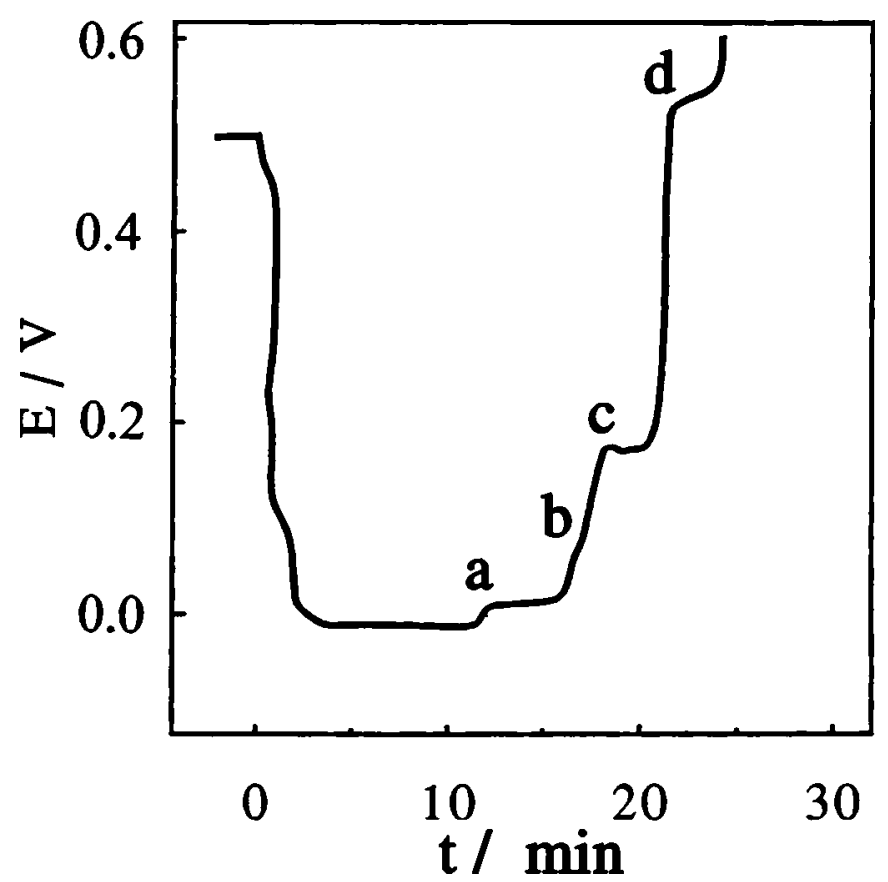

Figure 3. Current reversal chronopotentiogram at a nickel electrode in a $\mathrm{K}_{2} \mathrm{TiF}_{6}-\mathrm{NaCl}-\mathrm{KCl}-\mathrm{NaF}$ melt at $720^{\circ} \mathrm{C} . C_{\mathrm{Ti}}=0.1 \mathrm{~mol} / \mathrm{L}$. Electrode area: $0.32 \mathrm{~cm}^{2}$. Current $-4 \mathrm{~mA}(12 \mathrm{~min})$ and $+4 \mathrm{~mA}$. Potentials given $v s$. Ti/ $/ \mathrm{Ti}^{3+}$.

tion to the plateau a, which corresponds to dissolution of the pure titanium, two plateaus are clearly seen at 530 and $160 \mathrm{mV} v s$. $\mathrm{Ti} / \mathrm{Ti}^{3+}$. We may suggest that these are connected to the equilibrium reactions

$$
\begin{aligned}
& \mathrm{Ni}_{3} \mathrm{Ti}-3 \mathrm{e}^{-} \rightarrow \mathrm{Ni}+\mathrm{Ti}^{3+} \\
&\left(\text { plateau d, potential } E_{1}=530 \mathrm{mV}\right) \\
& 3 \mathrm{NiTi}-6 \mathrm{e}^{-} \rightarrow \mathrm{Ni}_{3} \mathrm{Ti}+2 \mathrm{Ti}^{3+}
\end{aligned}
$$$$
\text { (plateau c, potential } E_{2}=160 \mathrm{mV} \text { ) }
$$

Further, a shoulder (marked b at Fig. 3) is seen at a potential $E_{3}$ $=70 \mathrm{mV}$, which could have the same origin as $\mathrm{Ox}_{4^{\prime}}$ (Fig. 1 and 2). It may be related to the equilibrium

$$
\mathrm{NiTi}_{2}-3 \mathrm{e}^{-} \rightarrow \mathrm{NiTi}+\mathrm{Ti}^{3+}
$$

In a recent paper Robin ${ }^{18}$ also observed three steps connected to the dissolution of titanium-nickel alloys deposited from an all fluoride melt (FLINAK). The potential corresponding to the dissolution of $\mathrm{Ni}_{3} \mathrm{Ti}$ is in a good agreement with our value. For the other two potentials the values obtained by Robin are somewhat higher than ours.

The potential values are correlated to the thermodynamic properties of the alloys. According to the Reactions 1-3 the Gibbs energies of formation of the three alloys are linked to the $E$ values through the equations

$$
\begin{gathered}
\Delta G_{\mathrm{Ni} 3 \mathrm{Ti}}=-3 \mathrm{FE}_{1} \\
\Delta G_{\mathrm{NiTi}}=\left(-6 \mathrm{FE}_{2}+\Delta G_{\mathrm{Ni} 3 \mathrm{Ti}}\right) / 3 \\
\Delta G_{\mathrm{NiTi} 2}=-3 \mathrm{FE}_{3}+\Delta G_{\mathrm{NiTi}}
\end{gathered}
$$

Applying the measured potentials the following values are obtained

$$
\begin{aligned}
\Delta G_{\mathrm{Ni} 3 \mathrm{Ti}} & =-154 \mathrm{~kJ} \mathrm{~mol}^{-1} \\
\Delta G_{\mathrm{NiTi}} & =-82 \mathrm{~kJ} \mathrm{~mol}^{-1}
\end{aligned}
$$




$$
\Delta G_{\mathrm{NiTi} 2}=-102 \mathrm{~kJ} \mathrm{~mol}^{-1}
$$

These values are systematically greater (about 40\%), than the values given in Barin's handbook. ${ }^{19}$ To explain that divergence the presence of divalent titanium ions could be suggested in the mixed chloride-fluoride melts. Indeed, it is well known ${ }^{7,20}$ that, in pure alkali chloride melts, titanium ions in equilibrium with titanium metal exist mainly in the divalent form, $\mathrm{Ti}^{2+}$. However, this hypothesis is not likely to apply to our melts. Introducing alkali fluorides into the bath stabilizes the higher oxidation state. ${ }^{7,21}$ It has been shown ${ }^{7}$ that the amount of $\mathrm{Ti}^{2+}$ becomes very small for a molar ratio $\mathrm{F}^{-} / \mathrm{Ti}_{\text {ion }}$ greater than 6 . In the present electrolyte the ratio is around 50 which excludes the possibility of significant amount of $\mathrm{Ti}^{2+}$. This conclusion is confirmed by the recent work of Polyakova et al. ${ }^{9}$ who studied the reduction of titanium ions in nearly the same solvent as we apply. For the $\mathrm{Ni}_{3} \mathrm{Ti}$ alloy our result for the Gibbs energy of formation is in good agreement with the value measured by Gachon et al. ${ }^{22}$ It should be pointed out that the thermochemical measurement reported in the literature seems to disagree quite considerably. ${ }^{23}$

Oxide additions.-The obvious choice for a working electrode to investigate the influence of oxide would be tungsten. Unfortunately the waves on the cyclic voltammograms performed with tungsten electrodes merged to such an extent that made it impossible to distinguish any effect from the oxide additions. Consequently we have applied platinum indicator electrodes for our investigations. This offered the advantage of a large potential window but also a risk of perturbation from titanium-platinum alloy formation. The result can be seen in Fig. 4, that shows voltammograms recorded with platinum electrodes on melts with various oxides to titanium molar ratios. On the voltammogram with no oxide added (Fig. 4A) the waves $\mathrm{R}_{1}(-1.25 \mathrm{~V})$ and $\mathrm{Ox}_{1}$ occur at potentials very similar to what we found with tungsten electrodes (Fig. 1A). They are certainly due to the $\mathrm{Ti}(\mathrm{III}) / \mathrm{Ti}(\mathrm{IV})$ redox couple. We also recognize the reduction wave $R_{2}(-2.75 \mathrm{~V})$, which we have previously related to deposition of titanium metal. Indeed the corresponding oxidation wave, $\mathrm{Ox}_{2}$, has the typical shape of a stripping wave. Similar to the case with nickel electrodes, a reduction wave, $R_{3}(-2.00 \mathrm{~V})$, preceding the metal deposition wave can be observed. From experiments performed with different cathodic switching potentials it appears that the oxidation waves $\mathrm{Ox}_{3}$ and $\mathrm{Ox}_{3}^{\prime}$ are connected to $\mathrm{R}_{3}$. These waves can be explained as due to deposition and dissolution of Ti-Pt alloys. It is known from the phase diagram, ${ }^{24}$ that titanium and platinum form several intermetallic compounds, e.g., $\mathrm{Ti}_{3} \mathrm{Pt}$ and TiPt. Polyakova et al. ${ }^{9}$ found reductions, similar to our $\mathrm{R}_{1}$ and $\mathrm{R}_{3}$ waves. They also observed several oxidation waves, which were assigned to the dissolution of titanium-platinum alloys.

In Fig. 4B is a voltammogram of a melt with oxide added $(\mathrm{O} / \mathrm{Ti}$ molar ratio equal 0.44$)$. Clearly a new reduction wave $\mathrm{R}_{\mathrm{O} 1}(-1.81$ $\mathrm{V})$ appears at a potential more positive than the one for alloy formation $\left(R_{3}\right)$. It also seems that $R_{1}$ is disappearing. On the oxidation side the wave due to dissolution of metallic titanium $\left(\mathrm{Ox}_{2}\right)$ has obviously decreased upon oxide addition, and a wave $\mathrm{Ox}^{\prime}$, which appear at a potential near $\mathrm{Ox}_{3}^{\prime}$ (Fig. 4A) has grown. The voltammogram on Fig. $4 \mathrm{~B}$ with the less negative reverse potential could suggest that $\mathrm{Ox}^{\prime}$ to some extent is associated with $\mathrm{R}_{\mathrm{O} 1}$. With tungsten electrodes a small anodic peak, which may compare to our $\mathrm{Ox}^{\prime}$ peak, has been related to the presence of oxide in $\mathrm{K}_{2} \mathrm{TiF}_{6}-\mathrm{NaCl}-\mathrm{KCl}-\mathrm{NaF}$ melts. ${ }^{9}$ However no cathodic wave due to oxide as clear as $\mathrm{R}_{\mathrm{O} 1}$ has been observed previously.

The voltammogram of a sample with even more oxide added $(\mathrm{O} / \mathrm{Ti}=1.5)$ can be seen at Fig. 4C. Some interesting changes can be observed when we compare it to the voltammogram with less oxide added (Fig. 4B). It is obvious that the current due to titanium deposition (the $R_{2}$ wave) decreases considerably when more oxide is added. Second, a new reduction wave $\mathrm{R}_{\mathrm{O} 2}$ appears at $-1.50 \mathrm{~V}$. The shape of this wave is not what would be expected for a deposition

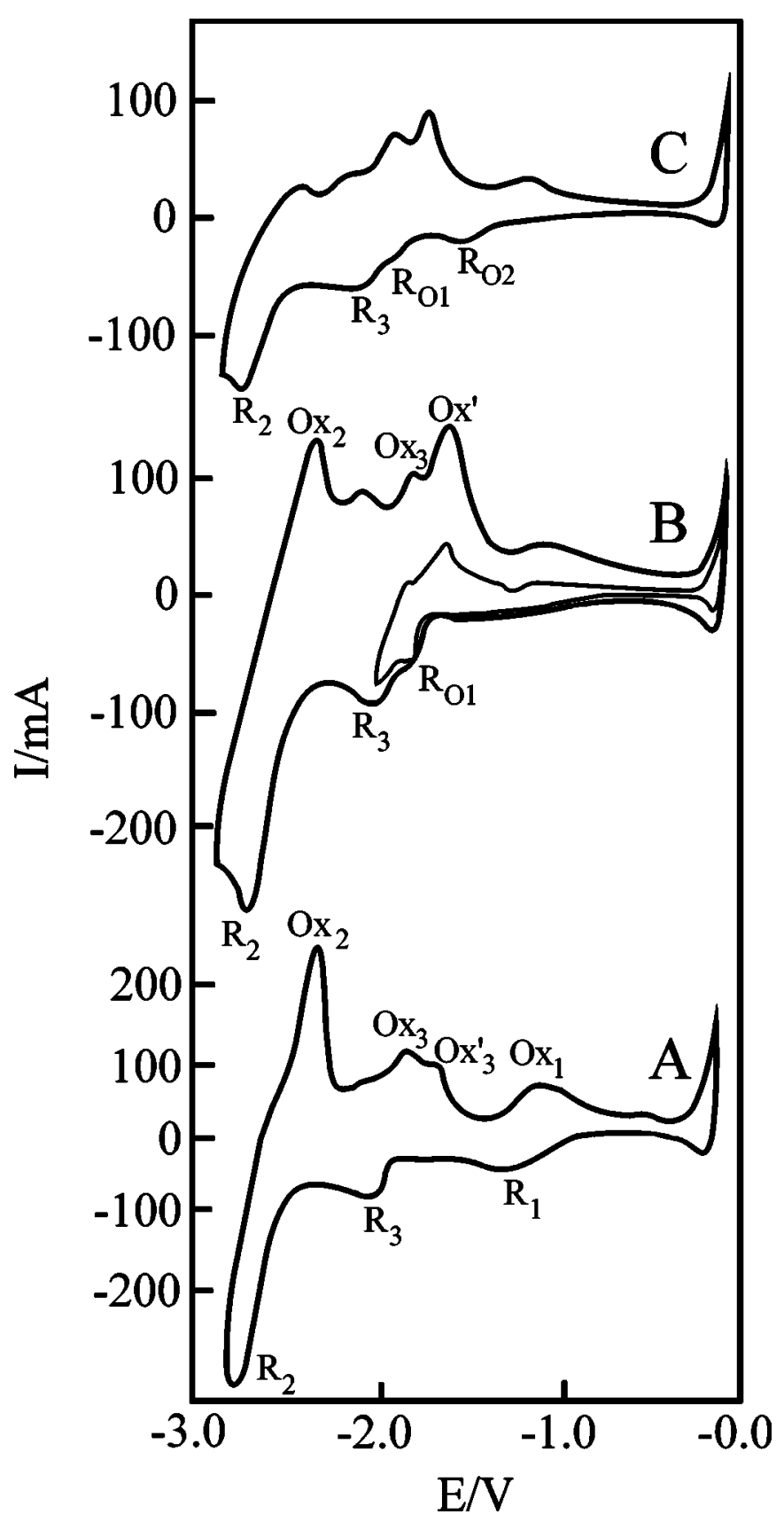

Figure 4. Cyclic voltammograms of $\mathrm{K}_{2} \mathrm{TiF}_{6}-\mathrm{NaCl}-\mathrm{KCl}-\mathrm{NaF}$ melts at $720^{\circ} \mathrm{C}$ with and without added oxide. Platinum working electrodes ( area $=0.31$ $\mathrm{cm}^{2}$ ), scan rate $1 \mathrm{~V} / \mathrm{s}$. (A) $C_{\mathrm{Ti}}=0.18 \mathrm{~mol} / \mathrm{L}$, no oxide added; (B) $C_{\mathrm{Ti}}$ $=0.18 \mathrm{~mol} / \mathrm{L}$ with $0.080 \mathrm{~mol} / \mathrm{L}$ oxide added; $(\mathrm{C}) C_{\mathrm{Ti}}=0.104 \mathrm{~mol} / \mathrm{L}$ with $0.156 \mathrm{~mol} / \mathrm{L}$ oxide added.

process; it rather resembles one of the homogeneous reactions in solution for the $\mathrm{Ti}(\mathrm{IV}) / \mathrm{Ti}(\mathrm{III})$ system. However it is not likely that it is due to reduction of a titanium(IV)-fluorocomplex since it appears at a potential different from $R_{1}$ in the melt without oxide added (Fig. 4A).

An explanation for these changes could be that the $\mathrm{R}_{\mathrm{O} 1}$ and $\mathrm{R}_{\mathrm{O} 2}$ waves arise from the reduction of two oxofluorotitanate complexes. It has recently been shown by vibrational spectroscopy that $\mathrm{TiF}_{6}^{2-}$ and $\mathrm{TiOF}_{5}^{3-}$ complexes are formed in FLINAK melts. ${ }^{25}$ Concerning $\mathrm{NaCl}-\mathrm{KCl}-\mathrm{NaF}$ melts our preliminary Raman results indicate, that $\mathrm{TiF}_{6}^{2-}$ also exists in the mixed fluoride-chloride medium (bands at 613 and $290 \mathrm{~cm}^{-1}$ ) and that oxofluoro complexes of the $\mathrm{TiOF}_{n}^{(n-2)-}$ 
type are formed when oxide is present (bands around $910 \mathrm{~cm}^{-1}$ ). In the FLINAK solvent we have observed two distinct vibrational bands in the 900 to $1000 \mathrm{~cm}^{-1}$ region for melts with an O/Ti molar ratio of 1.5 (i.e., similar oxide contents as the melt in Fig. 4C). This certainly suggests that more oxofluoro complexes may be involved. However to determine exactly which complexes we are dealing with more spectroscopic measurements will be needed.

Depositions.-The amount of materials involved in the electrochemical reaction in the transient technique investigations remain very small, around a few micromoles and the thickness of the deposit does not exceed a few atomic layers. To obtain thicker layers which could be analyzed by EDX and X-ray diffraction longer electrolysis must be performed. The nature and morphology of the deposits was also investigated in order to examine the ability of alloyed layers to form protecting coatings. Deposition on nickel substrates were performed at different constant potentials, constant currents, and with pulse current.

Figure 5A shows a SEM photograph of the surface of a constant potential deposit on a nickel plate maintained at $-2.06 \mathrm{~V}$ ( vs. $\mathrm{Pt} / \mathrm{Pt}^{2+}$ ) during 70 mins in a $\mathrm{Ti}(\mathrm{III})-\mathrm{NaCl}-\mathrm{KCl}-\mathrm{NaF}$ melt at $700^{\circ} \mathrm{C}$. The deposit consists of titanium crystals (according to EDX analysis) on top of the pure nickel substrate. The crystal adherence is poor and the cross-sectional analysis indicated that no intermediate alloy layers existed between the nickel substrate and the titanium crystals.

In Fig. 5 is further shown SEM photographs of the surface and cross section of a deposit on a nickel plate performed at a constant potential of $-1.635 \mathrm{~V}$ for $70 \mathrm{~min}$. From Fig. 5B it can be seen that the surface consists of a coherent layer of small $(\sim 1 \mu \mathrm{m})$ crystals. The SEM picture of the cross section (Fig. 5C) reveals that the deposit consists of two layers. Both the inner and the outer layer have a thickness of approximately $2 \mu \mathrm{m}$. The outer layer seems homogeneous and of uniform thickness. Between the inner layer and the substrate a Kirkendall layer appears. EDX analyses showed that the outer layer is composed of almost equal amounts (atom \%) of titanium and nickel, whereas the inner layer has a nickel-to-titanium atomic ratio near three. The X-ray diffractogram of the plate has lines, which can be assigned to NiTi (d values of 2.18 and $2.02 \AA$ ) and $\mathrm{Ni}_{3} \mathrm{Ti}$ (d values of $1.95,2.08$, and $2.13 \AA$, i.e., the three strongest lines). Since we deal with a rather thin deposit it is not surprising, that the strongest line due to nickel (from the substrate) was also observed. We have further performed deposition experiments with pulse current. Figure 6 shows SEM micrographs of such a deposit. The surface (Fig. 6A) consists of a coherent and wellcrystallized layer. EDX analysis showed that this layer was pure titanium metal. From the SEM photograph of the cross section (Fig. 6B) it appears that the coating is built up of three layers with a total thickness around $30 \mu \mathrm{m}$. Between the substrate and the inner layer a Kirkendall interface has formed. EDX analysis of the cross section indicated the presence of titanium metal (outer layer) and NiTi (middle layer). It was difficult to make an exact analysis of the rather thin inner layer; but the nickel contents increased when the substrate was approached. The X-ray diffractrogram showed lines due to titanium metal and NiTi.

A deposition at constant current $(-38 \mathrm{~mA})$ performed during 65 min in a melt with oxide added $(\mathrm{O} / \mathrm{Ti} \approx 1.5)$ resulted in the formation of a rather thin layer $(\approx 1 \mu \mathrm{m})$ with a few crystals on the top. EDX analysis of both the surface and cross section showed that the layer consisted of $\mathrm{Ni}$ and $\mathrm{Ti}$ in the proportion of 3:1. The crystals were pure titanium metal. A X-ray diffractogram confirmed that the layer was made of $\mathrm{Ni}_{3} \mathrm{Ti}$; the three strongest lines for this compound (d values of $1.95,2.08$, and $2.14 \AA$ ) were all observed. It seemed that no lines due to oxygenated species could be detected.

Our attempts to deposit $\mathrm{TiB}_{2}$ were more successful than previously. ${ }^{10}$ When depositions were performed at constant potential just after the addition of $\mathrm{KBF}_{4}$ to the $\mathrm{K}_{2} \mathrm{TiF}_{6}$-chloride-fluoride melt a well-crystallized and uniform surface layer could be obtained (Fig. 7). X-ray analyses showed that the layer consisted of pure $\mathrm{TiB}_{2}(\mathrm{~d}$ values of $1.37,1.51,2.04$, and $2.62 \AA$ ). Compared to our previous ${ }^{10}$

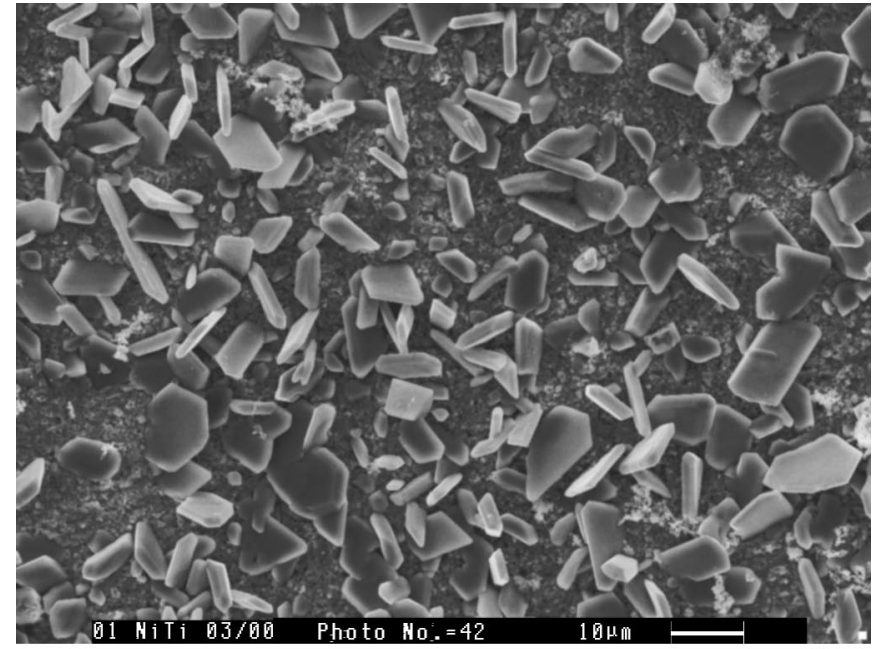

(A)

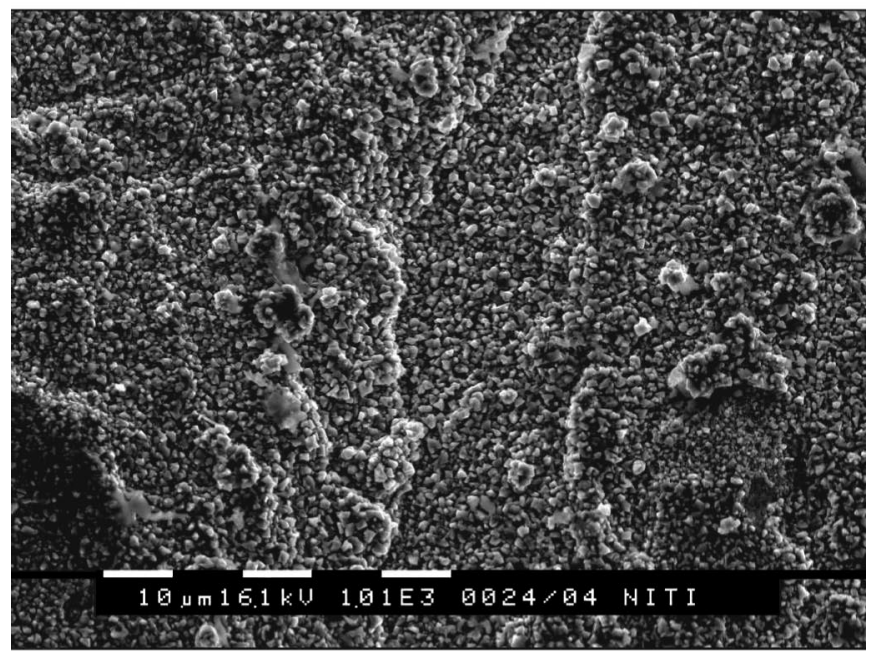

(B)

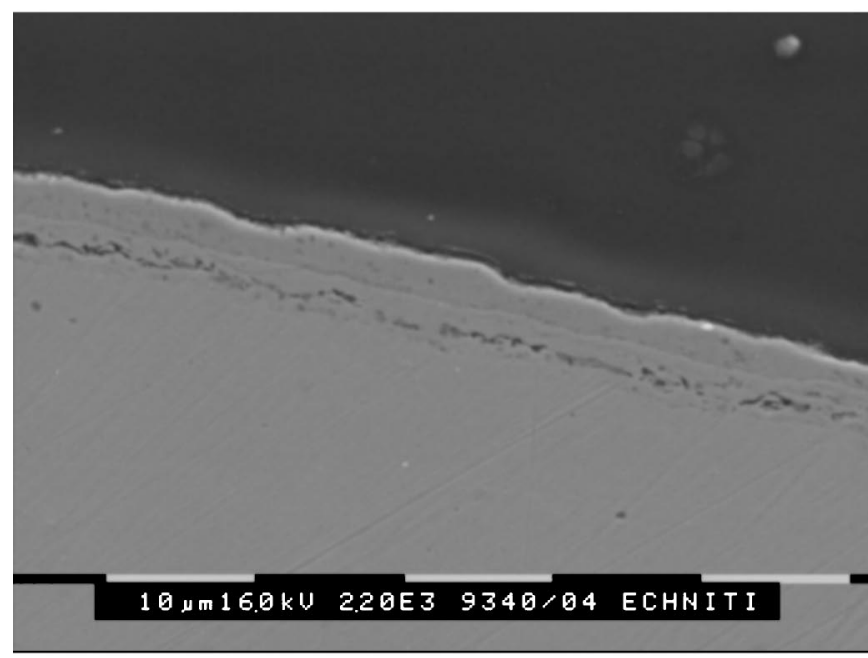

(C)

Figure 5. SEM micrographs of constant potential deposits on nickel plates from a NaCl-KCl-NaF- $\mathrm{K}_{2} \mathrm{TiF}_{6}$ melt with titanium metal added. $C_{\mathrm{Ti}}=0.30$ $\mathrm{mol} / \mathrm{L}$, temperature, $700^{\circ} \mathrm{C}$. (A) Fixed potential $-2.06 \mathrm{~V} v s$. $\mathrm{Pt} / \mathrm{Pt}^{2+}$ for $1 \mathrm{~h}$ $10 \mathrm{~min}$, surface (B) and (C). Fixed potential $-1.635 \mathrm{~V} v s . \mathrm{Pt} / \mathrm{Pt}^{2+}$ for $1 \mathrm{~h} 15$ min; (B) surface and (C) cross section. 


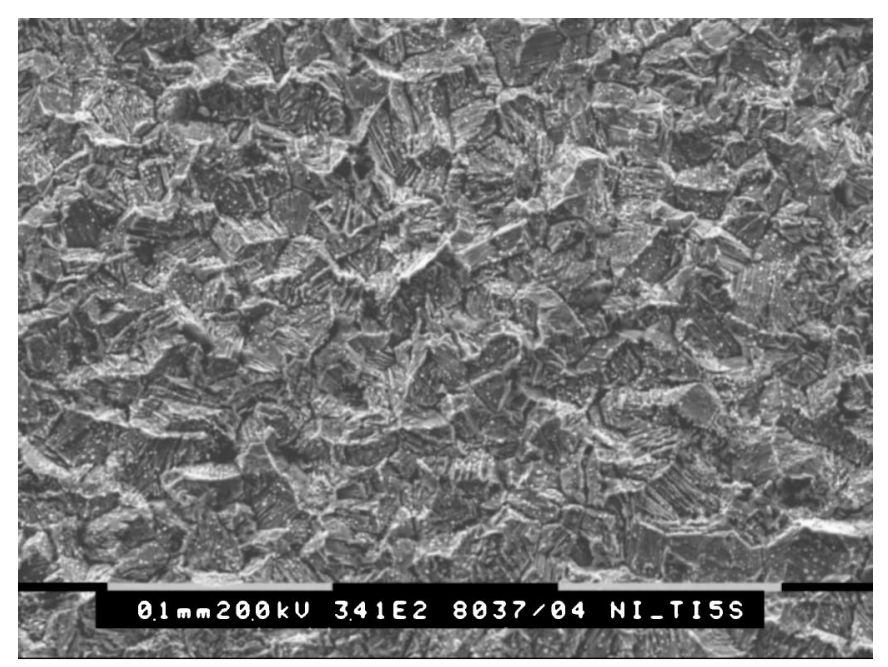

(A)

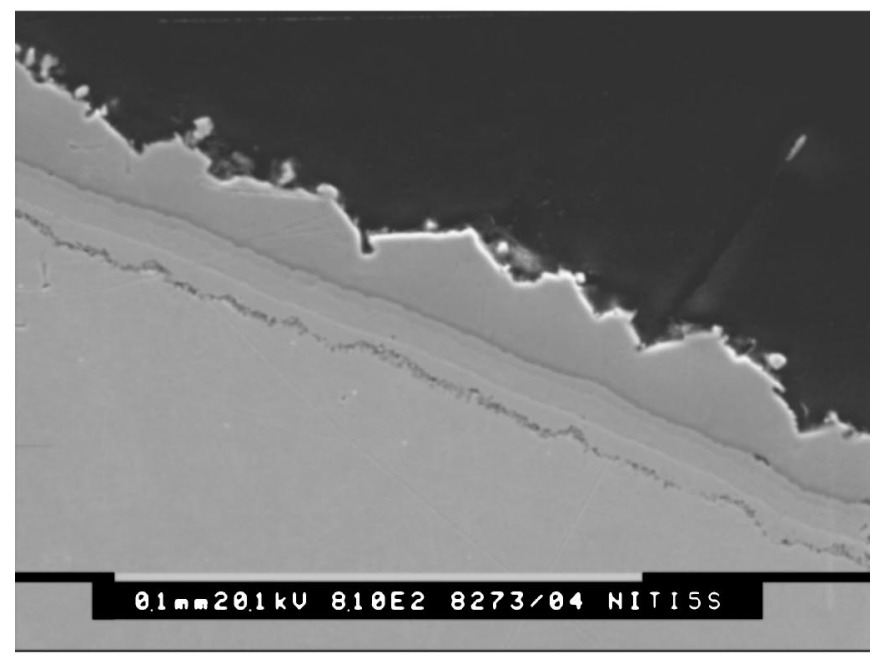

(B)

Figure 6. SEM micrographs of a pulse deposit on a nickel plate from a $\mathrm{NaCl}-\mathrm{KCl}-\mathrm{NaF}-\mathrm{K}_{2} \mathrm{TiF}_{6}$ melt reduced with titanium metal. Temperature: $720^{\circ} \mathrm{C} . C_{\mathrm{Ti}}=0.21 \mathrm{~mol} / \mathrm{L}$. Pulse conditions: $-3 \mathrm{~mA}$ in $22 \mathrm{~ms}$ and $-70 \mathrm{~mA}$ in $2 \mathrm{~ms}$, for $2 \mathrm{~h}, 40 \mathrm{~min}$ total. (A) Surface and (B) cross section.

plating experiments to obtain $\mathrm{TiB}_{2}$ the concentrations of titanium and boron solutes were doubled, and the deposition potential was also somewhat changed (from -2.2 to $-1.95 \mathrm{~V} v s$. $\mathrm{Pt} / \mathrm{Pt}^{2+}$ ). After some hours the melt seemed to be depleted in boron (due to the evaporation of approximately $10 \% / \mathrm{h}$ at $700^{\circ} \mathrm{C}$ ), and it was no longer possible to get good deposits.

\section{Conclusions}

The presence of oxide (in form of titanium oxofluoro species) can be detected as waves on the cyclic voltammograms. In general the use of a mixed fluoride-chloride melt as the supporting liquid seems to be a promising alternative to the all-fluoride melts for deposition processes involving titanium alloys and compounds. By electrolysis at various constant potentials surface layers of different $\mathrm{Ni}$-Ti alloys, e.g., NiTi (nitinol), could be deposited on nickel substrates. With pulse plating coherent nickel titanium multilayers with titanium metal as the outer layer were obtained from mixed chloride-fluoride melts. Also deposition of high quality $\mathrm{TiB}_{2}$ layers was possible from such melts. With the oxide present, only thin surface layers of $\mathrm{Ni}_{3} \mathrm{Ti}$ could be deposited.

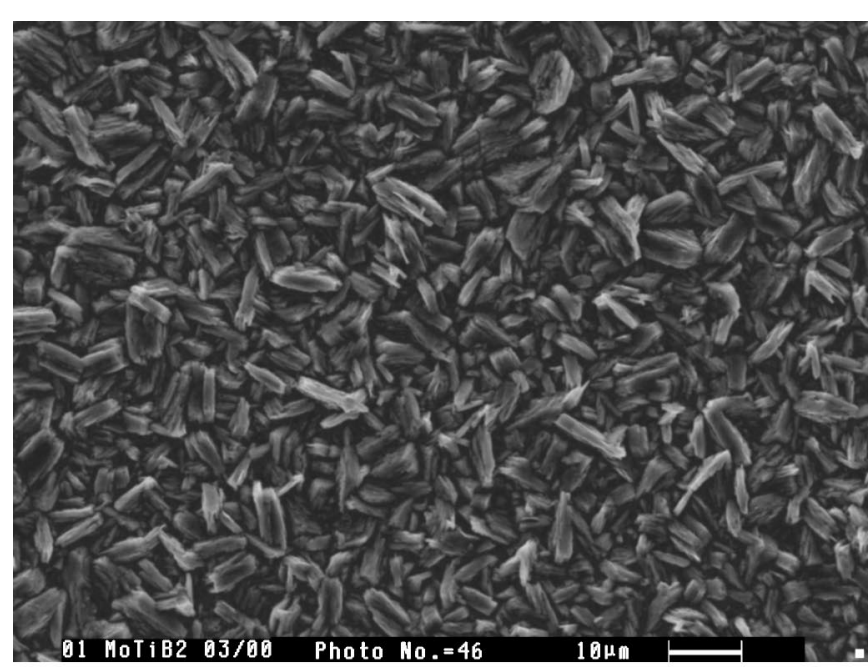

(A)

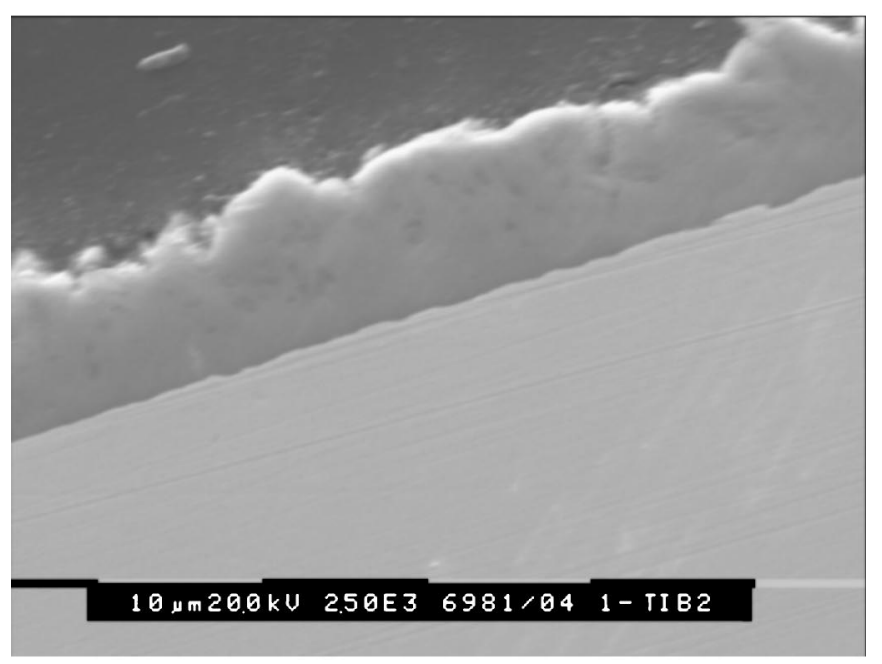

(B)

Figure 7. SEM micrografs of a constant potential deposit from a $\mathrm{NaCl}-\mathrm{KCl}-\mathrm{NaF}-\mathrm{K}_{2} \mathrm{TiF}_{6}-\mathrm{KBF}_{4}$ melt with titanium metal added on a molybdenum plate at $700^{\circ} \mathrm{C} . C_{\mathrm{Ti}}=0.30 \mathrm{~mol} / \mathrm{L}$ and $C_{\mathrm{B}}=0.600 \mathrm{~mol} / \mathrm{L}$. Deposition for $1 \mathrm{~h}, 30 \mathrm{~min}$, at $-1.95 \mathrm{~V}\left(v s . \mathrm{Pt}_{\mathrm{Pt}}{ }^{2+}\right)$. (A) Surface and (B) cross sections.

\section{Acknowledgments}

We are grateful for financial support from the Danish Technical Research Council. We further thank the French Foreign Ministry (The French Embassy in Copenhagen) for travel support.

Technical University of Denmark assisted in meeting the publication costs of this article.

\section{References}

1. A. Kapanen, J. Ilvasaro, A. Dadilov, J. Ryhänen, P. Lehenkari, and J. Tuukkanen, Biomaterials, 23, 645 (2002).

2. D. J. Wever, A. G. Veldhuiszen, M. M. Sanders, J. M. Schakenraad, and J. R. van Horn, Biomaterials, 18, 1115 (1997).

3. R. P. Pawlek, Alum. Trans., 3, 139 (2000).

4. F. R. Clayton, G. Mamantov, and D. L. Manning, J. Electrochem. Soc., 120, 1193 (1973).

5. A. Robin, J. de Lepinay, and M. J. Barbier, J. Electroanal. Chem., 230, 125 (1987).

6. F. Lantelme, K. Kuroda, and A. Barhoun, Electrochim. Acta, 44, 421 (1998)

7. F. Lantelme and A. Salmi, J. Electrochem. Soc., 142, 3451 (1995).

8. G. M. Haarberg, W. Rolland, A. Sterten, and J. Thonstad, J. Appl. Electrochem., 23, 217 (1993).

9. L. P. Polyakova, P. Taxil, and E. G. Polyakov, J. Alloys Compd., 359, 244 (2003).

10. F. Lantelme, A. Barhoun, E. M. Zahidi, and J. H. von Barner, Plasmas Ions, 2, 133 (1999). 
11. A. Robin and R. B. Ribeiro, J. Appl. Electrochem., 30, 239 (2000).

12. J. de Lépinay, J. Bouteillon, S. Traore, D. Renaud, and M. Barbier, J. Appl. Electrochem., 17, 294 (1987).

13. D. Wei, M. Okido, and T. Oki, J. Appl. Electrochem., 24, 923 (1994).

14. G. Kaptay and S. A. Kuznetsov, Plasmas Ions, 2, 45 (1999).

15. F. Lantelme, A. Barhoun, and J. Chevalet, J. Electrochem. Soc., 140, 324 (1993)

16. F. Lantelme and A. Salmi, J. Phys. Chem. Solids, 57, 1555 (1996).

17. ASM Handbook, Vol. 3, Alloy Phase Diagram, 2/319, ASM International, Park, OH (1992).

18. A. Robin, Mater. Lett., 34, 196 (1998).

19. I. Barin, Thermochemical Data of Pure Substances, 2nd Ed., Part II, pp. 10831084, VCH, Weinheim (1993).
20. D. M. Ferry, G. S. Picard, and B. Tremillon, J. Electrochem. Soc., 135, 1443 (1988).

21. T. Oki, M. Okido, and G.-S. Chen, in Molten Salts VI, G. Mamantov, M. Blander, C. Hussey, C. Mamantov, M.-L. Saboungi, and John Wilkes, Editors, PV 87-7, p. 507, The Electrochemical Society Proceedings Series, Pennington, NJ (1987).

22. J. C. Gachon, N. Notin, and J. Hertz, Thermochim. Acta, 48, 155 (1981).

23. L. Kaufman and H. Nesor, CALPHAD: Comput. Coupling Phase Diagrams Thermochem., 2, 81 (1978).

24. ASM Handbook, Vol. 3, Alloy Phase Diagram, 2/348, ASM International, Park, OH (1992).

25. C. Julien, R. W. Berg, and J. H. von Barner, in Progress in Molten Salt Chemistry 1, R. W. Berg and H. A. Hjuler, Editors, p. 253, Elsevier, Paris (2000). 